\title{
Cholelithiasis: A Brief Review on Diagnostic Approach and Management in Clinical Practice
}

\author{
Febyan ${ }^{1 *}$ and Ruswhandi ${ }^{2}$ \\ ${ }^{1}$ Faculty of Medicine, Krida Wacana Christian University, Indonesia \\ ${ }^{2}$ Department of Internal Medicine, Army Gatot Soebroto Hospital, Indonesia
}

Submission: April 24, 2020; Published: July 07, 2020

*Corresponding author: Febyan, Medical Doctor, Faculty of Medicine, Krida Wacana Christian University, Jakarta, Indonesia

\begin{abstract}
Cholelithiasis is one of the most prevalent diseases in gastroenterology. There are many factors in cholelithiasis, such as genetic, lack of physical activity, obesity, dietary, age, and other comorbidities. Commonly, cholelithiasis occurs asymptomatically; however, Murphy's sign is one of the most frequent pathognomonic findings in abdominal examination. Ultrasonography is known as the gold standard imaging examination in diagnosing cholelithiasis. The management of cholelithiasis can be divided into two categories, such as medical treatment and surgical treatment, which depends on the patient's condition.

Keywords: Gallstones; Cholelithiasis; Adults; Ultrasonography; Urxodeoxycholic acid; Laparoscopic cholecystectomy; Open cholecystectomy; Clinical practice

Abbreviations: UDCA: Ursodeoxycholic Acid; RCT: Randomized Controlled Trial; EASL: European Association for the Study of the Liver; NSAIDs: Nonsteroidal Anti-Inflammatory Drugs; ERCP: Endoscopic Retrograde Cholangiopancreatography; CT: Computed Tomography; USG: Ultrasonography; MRCP: Magnetic Resonance Cholangiopancreatography; WBC: White Blood Cell Count; CBC: Complete Blood Cell Count; RUQ: Right Upper Quadrant
\end{abstract}

\section{Introduction}

Cholelithiasis or gallstone is the presence of hardened deposits of digestive fluid that is formed in the gallbladder. The gallbladder is a small organ located just beneath the liver. It holds the digestive fluid known as bile, which will be released into the small intestine [1]. Cholelithiasis affects approximately 5.3$25 \%$ of the population, according to clinical survey reports from Europe, North and South America, and Asia [2,3]. Commonly, this disorder occurs asymptomatically, and only $20 \%$ of people with cholelithiasis experience pain and complications. The most common risk factor of cholelithiasis is gender, with females being one of the unmodifiable risk factors and is also related to metabolic syndrome events [4]. Pimpale et al. [5] stated that cholelithiasis is commonly found in females in the $4^{\text {th }}$ to $5^{\text {th }}$ decade of life, with abdominal pain being the most typical symptom. There are some other risk factors of cholelithiasis, such as genetics, the lack of physical activity which is also associated with metabolic syndrome, obesity which is related to the increase of cholesterol gallstones formation, dietary factors, and other comorbidities
[6]. This review is purposed to describe the diagnostic and management of cholelithiasis in clinical practice.

\section{Pathophysiology and Clinical Manifestation}

Cholesterol gallstones are formed mainly due to over secretion and saturation of cholesterol by liver cell; and hypomotility or impaired emptying of the gallbladder. In pigmented gallstones, conditions with high heme turnover, bilirubin may be present in bile at higher than normal concentrations. Bilirubin may then crystallize and eventually forms stones [7]. The manifestation of cholelithiasis is usually non-specific and not related to the presence of the gallstones. They include isolated heartburn, acid regurgitation, belching, nausea, vomiting, bloating, abdominal distension, chest pain, postprandial fullness or early satiety, and flatulence [8]. Visceral pain originates from the impact of the stone, or microlithiasis in the cystic duct or ampulla of Vater. This condition leads to distension and contraction from the gallbladder and the biliary tract. The intermittent increase of the pressure in 
the gallbladder activates visceral sensory neurons. The pain will be relieved if the stones move back into the gallbladder lumen, passes through the ampulla into the duodenum, or moves back to the common bile duct. The pain will develop as an intense and dull discomfort, either continuous or intermittent, with painful episodes ranging from hours to years [9]. During painful episodes, some non-specific gastrointestinal symptoms may occur, including $60 \%$ of cases manifested as radiating pain to the angle of the scapula or shoulder and less than $10 \%$ of cases to the retrosternal area. On the other hand, in two-thirds of patients experience colicky pain that is associated with the urgency to walk, nausea and vomiting, as well as diaphoresis; and this type of pain is usually not relieved by flatulence or bowel movements. The presence of fever, persistent tachycardia, hypotension, or jaundice in clinical findings, requires a search for complications of cholelithiasis, including cholecystitis, cholangitis, pancreatitis, or other systemic causes $[10,11]$.

In physical examination, the signs may appear as the jaundice and right upper quadrant (RUQ) tenderness during abdominal palpation. A positive Murphy's sign may also be elicited. In emergency cases, the Charcot triad (fever, RUQ tenderness, and jaundice) can be found, and it strongly indicates the presence of cholangitis, in which emergency treatment must be promptly done to prevent the further complications [12].

\section{Diagnostic Approach}

Diagnosis of cholelithiasis is established by performing history taking, physical examination, blood examination, ultrasonography.

\section{Laboratory tests}

Several laboratory tests should be considered in diagnosing cholelithiasis. A complete blood cell count (CBC) may show an elevated white blood cell count (WBC), although a normal WBC result sometimes does not necessarily exclude the possibility in establishing the diagnosis. Other laboratory components include the liver function test, lipase, amylase, urinalysis, pregnancy test in women of childbearing age, and stool guaiac test to rule out of intestinal bleeding, in case where the symptoms of the occult or massive gastrointestinal bleeding are present $[13,14]$.

\section{Imaging tests}

It is essential to have an accurate imaging modality in cholelithiasis to ensure early intervention and prevent complications (bacterial infection of the gallbladder, perforation, etc.). Imaging modality also can prevent unnecessary treatment in the event of false-positive findings. Some useful diagnostic tools are ultrasonography (USG), computed tomography (CT), magnetic resonance cholangiopancreatography (MRCP) [14].

Ultrasound is the method of choice and also known as the gold standard for diagnosing cholelithiasis. It is considered an excellent method because it has a precise diagnostic accuracy and may be performed to examine nearly all organs of the abdomen, regardless of its noninvasiveness, lacking of ionizing radiation, and relatively low cost. A study from Scruggs et al. found that the USG also has a high sensitivity (97\%) and specificity (93.6\%) $[15,16]$. The previous study reported that one of the most important advantages of USG over other imaging techniques in the investigation of cholelithiasis is the ability to assess for a sonographic Murphy's sign, which is a reliable indicator of cholelithiasis with sensitivity of $92 \%$. A wall thickening of the gallbladder in the presence of gallstones by USG has a positive predictive value of $95 \%$ for the diagnosis of cholelithiasis. Increased wall thickness of more than $3.5 \mathrm{~mm}$ is found to be a reliable finding of cholelithiasis [17]. Pericholecystic fluid (fluid around the gallbladder), distended gallbladder, edematous gallbladder, and gall rocks also can be significantly generated on USG. Color circulation Doppler USG may show hyperemic, pericholecystic blood flow, and acute inflammation. Visualization of USG findings usually shows mobile echogenic foci casting posterior acoustic shadows (Figure 1), and sometimes a wall echo-shadow indication is observed if the gallbladder is full of gallstones. This finding indicates cholelithiasis with cholecystitis consist of gallbladder distension (> $40 \mathrm{~mm}$ ) [18].

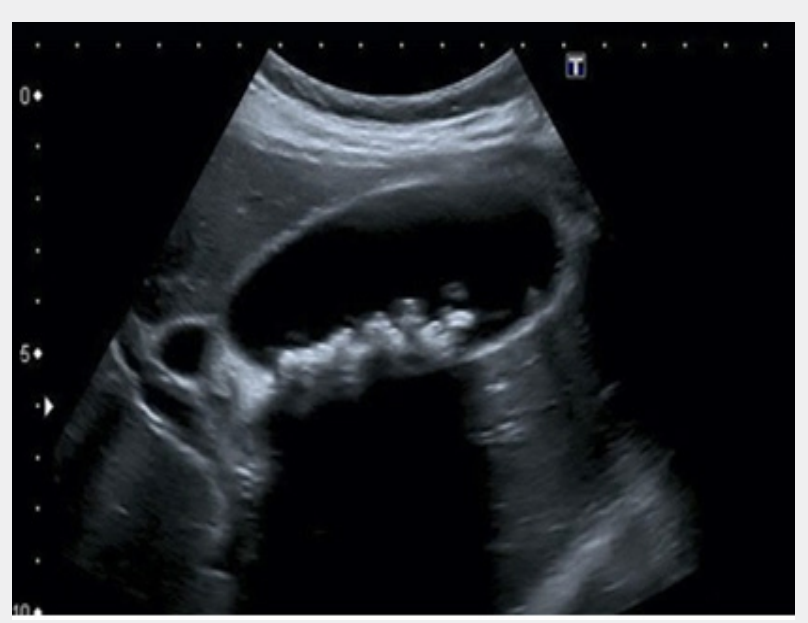

Figure 1: Cholelithiasis by Ultrasonographic. 
Although cholescintigraphy also has both high sensitivity and specificity (96\% and 90\%, respectively) for the diagnosis of cholelithiasis, this modality has several drawbacks that limit its use in clinical practice. This method is unable to assess structures outside of the biliary tract, and often lacks in readily available equipment and personnel, full of radiation exposure, and takes long hours to perform. It differs from USG that can be performed immediately and can confidently attribute localized pain to biliary pathology [19]. For undefined cases, CT or MRCP is considered as second-line modality that should be performed. Endoscopic retrograde cholangiopancreatography (ERCP), endoscopic ultrasonography, percutaneous transhepatic cholangiography are also recommended. The clinician needs to know about the stepwise when undefined cases are found (Figure 2).

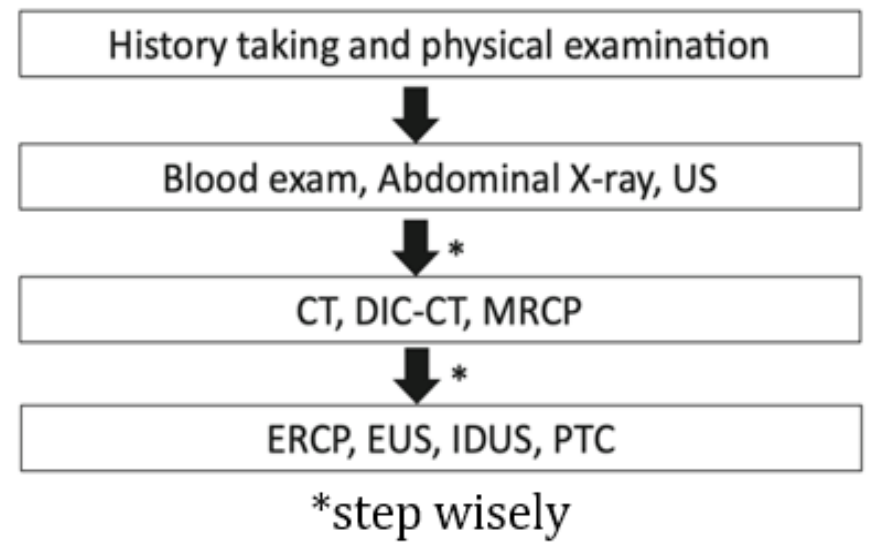

Figure 2: Flowchart for diagnosis of cholelithiasis [20].

\section{Management}

\section{Medical treatment}

Treatment of colicky pain primarily involves pain control with nonsteroidal anti-inflammatory drugs (NSAIDs) or narcotic pain relievers, and also may be accompanied by symptomatic treatment for nausea, vomiting, and fever as needed. Another option for pain control is the anti-spasmodic agent (hyoscine-N-butyl bromide), which is used to relax and relieve the spasms of the gallbladder. However, comparison studies have shown that NSAIDs provide faster and work more effectively as a pain reliever. The patient should fast as part of the conservative management of colicky pain and to avoid the release of endogenous cholecystokinin [2022]. A study from the European Association for the Study of the Liver (EASL) showed that the ursodeoxycholic acid (UDCA) is not indicated as a preventive medication for gallstone disease in the general population [23]. Otherwise, prophylactic UDCA (500 g/d) may prevent stone formation for those patients with post-bariatric surgery [23]. A randomized controlled trial (RCT) study published in 2003 found a significantly reduced risk of gallstones formation within 24 months after restrictive gastric bypass surgery ( $8 \%$ vs. 30\%) [24].

A study by Kotb (2012) reported that UDCA might also reduce gallstones by the dissolution process in cholelithiasis patients that had confirmed by USG. Ursodeoxycholic acid has been shown to decrease biliary colic, with administration of UDCA for over 6 to 18 months at the dose of $8-10 \mathrm{mg} / \mathrm{kg}$ per day divided into 2 to 3 times daily. The recurrence rate in patients who are treated with gallstone dissolution agents is $50 \%$ within five years [25]. There are some side effects, including immune suppression, diarrhea, liver failure, portal hypertension, thrombocytopenia, and pruritus. Thus, the patients who are using UDCA should be monitored appropriately [26].

\section{Surgical treatment}

Surgical management for patients with symptomatic gallstones can be divided into two categories; (1) those who have simple biliary colic and (2) those with complications. Most patients with symptomatic gallstones can be treated using laparoscopic cholecystectomy. But Cochrane review of laparoscopic cholecystectomy versus open cholecystectomy showed the similar results in complication rates and surgical time, but a shorter hospital stays (three fewer days; 95\% CI, 2.3 to 3.9 days) and shorter convalescence period (22 fewer days; 95\% CI 8 to 37 days) [27]. Many factors that increase the risk of conversion to open cholecystectomy include male sex, age 60 years or older, previous upper abdominal surgery, thickened gallbladder wall on ultrasonography, and acute cholecystitis [28]. Table 1 provides the indications and contraindications for laparoscopic cholecystectomy. 
Table 1: Indications and Contraindications of Laparoscopic Cholecystectomy [29].

\begin{tabular}{|r|}
\hline Indications \\
\hline Biliary dyskinesia, acute cholecystitis, gallstones (symptomatic or asymptomatic), complications related to common bile duct stones. \\
\hline Contraindications \\
\hline Absolute: uncontrolled coagulopathy, inability to tolerate general anesthesia, all types of gallbladder cancer. \\
\hline Relative: severe acute peritonitis, septic shock, advanced cirrhosis/liver failure, previous upper abdominal surgeries, peritonitis. \\
\hline
\end{tabular}

Antibiotics pre-operation is not indicated in low-risk patients undergoing elective surgery, but it may reduce the incidence of wound infection after laparoscopic cholecystectomy in highrisk patients such as geriatric patient, comorbidities (diabetes mellitus, jaundice, cholangitis) [29,30]. The European Association for the Study of the Liver recommends to limit the use of antibiotic prophylaxis to a single preoperative dose of intravenous cefazolin as much as 1 gram, given within one hour of skin excision [23].

\section{Conclusion}

In conclusion, cholelithiasis refers to the formation of gallstones and may present with or without any obvious symptoms. Because cholelithiasis is a multifactorial disease, prompt and structured diagnostic approaches, including history taking, physical examination, laboratory tests, and imaging tests, should be performed to decide the management properly and minimize false-positive events.

\section{References}

1. Chung AY, Duke MC (2018) Acute biliary disease. Surg Clin North Am 98(5): 877-894

2. Stinton LM, Myers RP, Shaffer EA (2010) Epidemiology of gallstones. Gastroenterol Clin North Am 39(2): 157-169.

3. Festi D, Reggiani MLB, Attili AF (2010) Natural history of gallstone disease: Expectant management or active treatment? Results from a population-based cohort study. J Gastroenterol Hepatol 25(4): 719724.

4. Cojocaru DC, Mitu F, Dascalu CG, Manole A, Cozma CD (2014) The predictor of cholelithiasis in female patients with metabolic syndrome. Cent. Eur J Med 9(1): 108-114.

5. Pimpale R, Katakwar P, Akhtar M (2019) Cholelithiasis: causative factors, clinical manifestations and management. Int Surg J 6(6): 21332138.

6. Peswani AR, Sequeira VJ, D'silva M, Ghanwat S, Shah PP, Pinto AC (2019) Association between gallstone disease and metabolic syndrome. IJCMR 6(10): J1-J5.

7. Chen Y, Kong J, Wu S (2015) Cholesterol gallstone disease: focusing on the role of gallbladder. Laboratory Investigation 95: 124-131.

8. Lammert F, Gurusamy K, Ko CW (2016) Gallstones. Nat Rev Dis Primers 2:16025.

9. Shabanzadeh DM (2018) Incidence of gallstone disease and complications. Curr Opin Gastroenterol 34(2): 81-89.

10. Portincasa P, Moschetta A, Palasciano G (2006) Cholesterol gallstone disease. Lancet 368(9531): 230-239.
11. Reshetnyak VI (2012) Concept of the pathogenesis and treatment of cholelithiasis. World J Hepatol 4(2): 18-34.

12. Gore JM (2013) Cholelithiasis. JAAPA 26(12): 54-55.

13. Thomas S (2013) Differentiating abdominal pain using Murphy's sign. Practice Nurs 24(3):141.

14. Aslam HM, Saleem S, Edhi MM (2013) Assessment of gallstone predictor: comparative analysis of ultrasonographic and biochemical parameters. Int Arc Med 6: 17.

15. Scruggs W, Fox JC, Potts B, Zlidenny A, McDonough J (2008) Accuracy of ED bedside ultrasound for identification of gallstones: retrospective analysis of 575 studies. West J Emerg Med 9(1): 1-5.

16. Gijaca V, Gurusamy KS, Takwoingi Y (2015) Endoscopic ultrasound versus magnetic resonance cholangiopancreatography for common bile duct stones. Cochrane Database Syst Rev 15(2): CD011549.

17. Khan SP, Izhar $S$ (2018) Ultrasound as a first line investigation of choice in diagnosis acute cholicystitis. IJAR 6(11): 65-69.

18. van Breda V, Engerbrecht MR, Smithuis RH, Puylaert JB (2007) Diffuse gallbladder wall thickening: differential diagnosis. AJR 188: 495-501.

19. Alobaide M, Gupta R, Jafri SZ, Fink-Bennet DM (2004) Current trends in imaging evaluation of acute cholecystitis. Emer Radiol 10(5): 256-258.

20. Tazuma S, Unno M, Igarashi Y, Inui K, Uchiyama K, Kai M, et al (2017) Evidence-based clinical practice guidelines for cholelithiasis 2016. Gastroenterol 52(3): 276-300.

21. Henderson SO, Swadron S, Newton E (2022) Comparison of intravenous ketorolac and meperidine in the treatment of biliary colic. J Emerg Med 23(3): 237-241.

22. Kumar A, Deed JS, Bhasin B, Kumar A, Thomas S (2004) Comparison of the effect of diclofenac with hyoscine-N-butylbromide in the symptomatic treatment of acute biliary colic. ANZ J Surg 74(7): 573576.

23. European Association for the Study of the Liver (2016) EASL clinical practice guidelines on the prevention, diagnosis and treatment of gallstones. Journal of Hepatology 65: 146-181.

24. Gutt C, Schlafer S, Lammert F (2020) The treatment of gallstone disease. Dtsch Arztebl Int 117(9): 148-158.

25. Kotb MB (2012) Molecular mechanism of ursodeoxycholic acid toxicity \& side effects: ursodeoxycholic acid freezes regeneration \& induces hibernation mode. Int J Mol Sci 12(7): 8882-8914.

26. Guarino MP, Cocca S, Altomare A, Emerenziana S, Cicala M (2013) Ursodeoxycholic acid therapy in gallbladder disease, a story not yet completed. World J Gastroenterol 19(31): 5029-5034.

27. Keus F, de Jong JA, Gooszen HG, van Laarhiven CJ (2006) Laparoscopic versus open cholecystectomy for patients with symptomatic cholecystolithiasis. Cochrane Database Syst Rev 4: CD006231. 
28. Tayeb M, Raza SA, Khan MR, Azami R (2005) Conversion from laparoscopic to open cholecystectomy: multivariate analysis of preoperative risk factors. J Postgrad Med 51(1): 17-20.

29. Peitzman AB, Watson GA, Marsh JW (2014) Acute cholecystitis: when to operate and how to do it safely. J Trauma Acute Care Surg 78(1): 1-12.
30. Manes G, Paspatis G, Aabakken L, Anderloni A, Arvanitakis M, AhSaune P (2019) Endoscopic management of common bile duct stone: European society of gastrointestinal endoscopy (ESGE) guideline. Endoscopy 51(5): 472-491.

\section{Your next submission with JuniperPublishers} will reach you the below assets

- Quality Editorial service

- Swift Peer Review

- Reprints availability

- E-prints Service

- Manuscript Podcast for convenient understanding

- Global attainment for your research

- Manuscript accessibility in different formats ( Pdf, E-pub, Full Text, audio)

- Unceasing customer service

Track the below URL for one-step submission https://juniperpublishers.com/online-submission.php 